\title{
Recent Trends in Cost-Related Medication Nonadherence among Stroke Survivors in the United States
}

\author{
Deborah A. Levine, MD, MPH, ${ }^{1,2,3}$ Lewis B. Morgenstern, MD, ${ }^{3,4}$ \\ Kenneth M. Langa, MD, PhD, 1,2,5 John D. Piette, PhD, 1,2 \\ Mary A. M. Rogers, $\mathrm{PhD}^{1}$ and Sudeep J. Karve, $\mathrm{PhD}^{6}$
}

Objective: Recent economic and health policy changes may have affected the ability of chronically ill patients to afford their medications. We assessed changes in cost-related nonadherence to medication (CRN) before and after the implementation of Medicare Part D in 2006.

Methods: We used data from the National Health Interview Survey, an annual, population-based survey of community-dwelling, noninstitutionalized US adults, to estimate CRN in 8,673 stroke survivors aged 45 years or older, representing 4.8 million survivors, for the years 1999 to 2010 . The main outcome measure was CRN, defined as self-reported inability to afford prescribed medication within the past 12 months.

Results: During the period 1999 to 2010, 11.4\% of stroke survivors, approximately 543,000 individuals, reported CRN. From 1999 to 2010, CRN more than doubled among stroke survivors aged 45 to 64 years (from 12.7 to $26.5 \%$; $p_{\text {trend }}=0.01$ ). CRN remained stable among those aged 65 years or older (from 3.8 to $7.0 \% ; p_{\text {trend }}=0.21$ ). From 1999-2005 to 2006-2010, CRN among uninsured stroke survivors aged 45 to 64 years increased from 43.1 to $57.1 \%$ $(p=0.03)$. Among stroke survivors aged 65 years or older with Medicare coverage, CRN was higher among Medicare Part D participants than those without the drug benefit (7.9 vs 4.8\%; $p=0.02$ ). After adjustment for sociodemographic and clinical factors, CRN was similar among Medicare Part D enrollees and nonenrollees.

Interpretation: From 1999 to 2010, CRN increased significantly among stroke survivors younger than 65 years, particularly among those without health insurance. There was no evidence that Medicare Part D decreased CRN among stroke survivors with Medicare.

ANN NEUROL 2013;73:180-188

$T_{\mathrm{m}}^{\mathrm{h}}$ he ability of chronically ill adults to afford their medications is a critical public health issue. Costrelated nonadherence to medication (CRN) is associated with recurrent vascular events, health declines, worse quality of life, and death. ${ }^{1-3}$ Financial barriers contribute to $>60 \%$ of medication nonfulfillment and $45 \%$ of medication nonpersistence among US adults with hypertension or diabetes, 2 major cerebrovascular risk factors. ${ }^{4}$

In 2006, the US government implemented the Medicare Part D drug benefit, which allowed Medicarecovered adults to purchase insurance for prescription drug coverage. This intervention aimed to reduce CRN in older or disabled adults. However, the recent economic downturn may have disproportionally worsened CRN in chronically ill adults younger than 65 years, because they are more likely to live in poverty, be uninsured, or have high out-of-pocket medical expenses. ${ }^{5-7}$

Stroke survivors represent an ideal group in which to study the impact of Medicare Part D on reducing CRN in chronically ill adults. Stroke is common in older adults and is the leading cause of adult disability. ${ }^{8}$ By 2030, the United States is projected to have an

View this article online at wileyonlinelibrary.com. DOI: 10.1002/ana.23823

Received Jun 21, 2012, and in revised form Oct 22, 2012. Accepted for publication Nov 5, 2012

Address correspondence to Dr Levine, University of Michigan Division of General Medicine, North Campus Research Complex, 2800 Plymouth Road, Building 16, Room 430W, Ann Arbor, Ml 48109-2800. E-mail: deblevin@umich.edu

From the ${ }^{1}$ Division of General Medicine, University of Michigan Health System, and Ann Arbor VA Healthcare System, Ann Arbor, Ml; ${ }^{2}$ Veterans Affairs Health Services Research and Development Center of Excellence, Ann Arbor, Ml; ${ }^{3}$ Stroke Program, University of Michigan Health System, Ann Arbor, Ml; ${ }^{4}$ Department of Epidemiology, University of Michigan School of Public Health, Ann Arbor, Ml; ${ }^{5}$ nstitute for Social Research, University of Michigan, Ann Arbor, Ml; and ${ }^{6}$ Department of Health Economics, RTI Health Solutions, Research Triangle Park, NC. 
additional 4 million stroke survivors, a $25 \%$ increase in prevalence from 2010. ${ }^{9}$ Stroke survivors have a high risk of cardiovascular events, including a 4 to $15 \%$ annual risk of recurrent stroke. ${ }^{8}$ These complications increase stroke patients' morbidity, disability, and health care costs. ${ }^{8,10}$ Randomized trials have demonstrated that antithrombotic drugs, antihypertensive drugs, and 3-hydroxy-3-methylglutaryl coenzyme A reductase inhibitors (statins) are effective in preventing further disability and morbidity in stroke survivors, ${ }^{11-14}$ and as many as $80 \%$ of recurrent strokes may be prevented with pharmacotherapy. ${ }^{15}$ However, for stroke survivors, medications may be inaccessible due to costs. Stroke survivors have high prescription medication needs and costs ${ }^{16}$ and have greater health-related financial burdens than patients with other chronic diseases. ${ }^{17}$

Little is known about how recent policy and economic changes may have affected the ability of US stroke survivors to afford their medications over time. Therefore, we assessed CRN by age and insurance, including Medicare Part D, and across time in a national sample of US stroke survivors. We hypothesized that, from 1999 to 2010, CRN increased in younger stroke survivors (aged 45-64 years), increased in the uninsured (aged 45-64 years), and decreased among Medicare patients with access to the Part D drug benefit.

\section{Patients and Methods}

\section{Data Source}

The National Health Interview Survey (NHIS) is an ongoing, household survey of the civilian, noninstitutionalized US population conducted annually by the National Center for Health Statistics (NCHS) using face-to-face interview. ${ }^{18}$ NHIS used similar survey designs and data collection methods between 1999 and 2010, and sample adults had conditional response rates of 74 to $84 \% .{ }^{18}$ Data were obtained from the Integrated Public Use Microdata Series (Minnesota Population Center and State Health Access Data Assistance Center, Integrated Health Interview Series; version 5.0, University of Minnesota) and the NCHS ${ }^{18}$ If the subject is physically or mentally unable to answer the survey questions, then a knowledgeable proxy provides answers (200-350 cases per year). ${ }^{18}$

\section{Study Population}

We identified stroke survivors as respondents who answered yes to the question, "Have you ever been told by a doctor or other health professional that you had a stroke?" The 1999-2010 NHIS sampled from all US states and the District of Columbia and was designed to produce representative population-based estimates for the entire United States. ${ }^{18}$ Of 8,752 NHIS respondents aged 45 years or older reporting a physician diagnosis of stroke, we excluded $79(0.9 \%)$ who did not provide information on CRN, leaving 8,673 available for analysis.

\section{Outcome Measure}

CRN was defined by the answer to: "During the past 12 months, was there any time when you needed prescription medicines, but didn't get [them] because you couldn't afford [them]?" The inability to afford medications increases the probability of stroke preventive medication underuse attributable to cost by more than 2-fold among stroke survivors. ${ }^{19}$ Moreover, financial barriers increase the risk of nonadherence to statins, antihypertensive medications, and clopidogrel..$^{20,21}$

\section{Statistical Analysis}

The frequency of CRN across individual years (1999-2010) was compared using the Cochran-Mantel-Haenszel chi-square test for trend, and US population-weighted estimates were calculated. Analyses were conducted for the overall sample and within 2 age strata ( $<65$ vs $\geq 65$ years), because US adults generally qualify for Medicare health insurance at age 65, and age modifies access to medications among stroke survivors. ${ }^{22}$ In the United States, stroke survivors younger than 65 years qualify for Medicare health insurance if they have been receiving Social Security or Railroad Retirement Board disability benefits for 2 or more years. ${ }^{23}$ Within each age stratum, we compared the frequency of CRN by insurance and time before and after Medicare Part D implementation (1999-2005 vs 2006-2010) using Wald chi-square.

Respondent characteristics were compared between age or insurance groups using Wald chi-square test or $t$ test. Covariates were selected based on literature review and the Andersen Behavioral Model. ${ }^{24}$ Covariates included age, sex, race (white, black, or other), Hispanic ethnicity, education $(<$ high school, high school, some college, $\geq$ college), the ratio of family income to poverty threshold $(<1.0,1.0-1.99$, $\geq 2.00$, missing/unreported), and health insurance (private coverage with or without Medicare, Medicaid and Medicare, Medicare only, other insurance, uninsured). Respondents also reported whether they were enrolled in Medicare Part D during the current survey year, which corresponds to the calendar year. Medicare Part D coverage is assumed to be for the entire year, because Medicare policy does not permit disenrollment from Medicare Part D during a calendar year. ${ }^{23}$ Self-reported health status was dichotomized as low (fair or poor) or high (excellent, very good, or good). A comorbidity score was calculated using a modified Charlson Index validated for use in stroke outcome studies. ${ }^{25}$ Functional disability was defined as a health problem that led to difficulty with $\geq 1$ functional activity (eg, walking a quarter mile, lifting/carrying 10 pounds).

Multivariable logistic regression analyses, stratified by the 2 age groups, were performed to examine the adjusted associations between insurance and time and the outcome measure, CRN. Time was examined as a continuous variable or as a binary variable (1999-2005 vs 2006-2010). We examined the effect of sequential addition of factors to the models. We obtained estimates and standard errors of predicted marginals 


\begin{tabular}{|c|c|c|c|c|}
\hline \multirow[t]{2}{*}{ Study Cohort } & \multicolumn{2}{|c|}{ Age 45-64 Years } & \multicolumn{2}{|c|}{ Age $\geq 65$ Years } \\
\hline & $\begin{array}{l}\text { Years } \\
1999-2005\end{array}$ & $\begin{array}{l}\text { Years } \\
2006-2010\end{array}$ & $\begin{array}{l}\text { Years } \\
1999-2005\end{array}$ & $\begin{array}{l}\text { Years } \\
2006-2010\end{array}$ \\
\hline No.; population estimate & 1,$687 ; 850,925$ & 1,$254 ; 874,267$ & 3,$572 ; 1,697,684$ & 2,$160 ; 1,348,079$ \\
\hline Mean age, years $(95 \% \mathrm{CI})$ & $55.9(55.6-56.2)$ & $55.9(55.5-56.2)$ & $76.2(75.9-76.4)$ & $76.5(76.1-76.8)$ \\
\hline Female, \% (95\% CI) & $48.4(45.6-51.3)$ & $50.7(47.2-54.1)$ & $54.6(52.7-56.4)$ & $55.0(52.4-57.6)$ \\
\hline \multicolumn{5}{|l|}{ Race, \% (95\% CI) } \\
\hline White & $74.7(72.2-77.1)$ & $76.3(73.5-78.8)$ & $86.1(84.7-87.3)$ & $83.8(82.2-85.3)$ \\
\hline Black & $18.2(16.2-20.4)$ & $17.9(15.6-20.5)$ & $9.8(8.8-10.9)$ & $11.6(10.4-13.0)$ \\
\hline Other & $7.1(5.7-8.8)$ & $5.8(4.3-7.9)$ & $4.2(3.5-5.1)$ & $4.6(3.7-5.6)$ \\
\hline $\begin{array}{l}\text { Hispanic ethnicity, } \\
\%(95 \% \mathrm{CI})\end{array}$ & $8.2(7.0-9.5)$ & $10.2(8.5-12.2)$ & $5.8(5.0-6.8)$ & $5.7(4.8-6.7)$ \\
\hline \multicolumn{5}{|l|}{ Education, \% (95\% CI) } \\
\hline$<$ High school & $27.3(24.9-29.8)$ & $22.4(19.6-25.3)$ & $38.6(36.7-40.5)$ & $32.5(30.1-35.0)$ \\
\hline High school & $36.0(33.3-38.7)$ & $32.3(28.9-35.9)$ & $31.1(29.4-32.9)$ & $32.0(29.6-34.5)$ \\
\hline Some college & $24.7(22.4-27.2)$ & $31.4(28.2-34.8)$ & $17.7(16.3-19.1)$ & $20.6(18.7-22.8)$ \\
\hline$\geq$ College & $12.0(10.2-14.0)$ & $13.9(11.5-16.7)$ & $12.7(11.4-14.0)$ & $14.9(13.0-16.9)$ \\
\hline \multicolumn{5}{|l|}{ Insurance, \% (95\% CI) } \\
\hline Private and Medicare & $6.3(5.0-8.0)$ & $6.6(5.1-8.6)$ & $54.5(52.6-56.4)$ & $51.8(49.1-54.4)$ \\
\hline Private only & $44.3(41.6-47.1)$ & $39.2(35.8-42.6)$ & $4.0(3.3-4.9)$ & $1.7(1.1-2.6)$ \\
\hline Medicare only & $10.9(9.3-12.7)$ & $13.1(10.8-15.7)$ & $24.8(23.2-26.5)$ & $27.7(25.5-30.1)$ \\
\hline Other & $27.9(25.5-30.4)$ & $29.4(26.4-32.6)$ & $15.8(14.5-17.1)$ & $18.3(16.5-20.2)$ \\
\hline Uninsured & $10.6(9.0-12.5)$ & $11.8(9.9-14.0)$ & $1.0(0.6-1.7)$ & $0.5(0.3-1.1)$ \\
\hline Any Medicare insurance & $25.8(23.4-28.3)$ & $29.5(26.4-32.8)$ & $92.9(91.8-93.9)$ & $96.4(95.3-97.3)$ \\
\hline \multicolumn{5}{|l|}{$\begin{array}{l}\text { Family income to poverty } \\
\text { ratio, \% (95\% CI) }\end{array}$} \\
\hline$<1.00$ & $17.4(15.5-19.4)$ & $19.9(17.6-22.4)$ & $9.3(8.3-10.3)$ & $10.0(8.8-11.3)$ \\
\hline $1-1.99$ & $19.3(17.2-21.6)$ & $22.9(20.1-26.0)$ & $22.1(20.6-23.7)$ & $22.0(19.9-24.2)$ \\
\hline$\geq 2.00$ & $40.5(37.8-43.3)$ & $46.7(43.3-50.2)$ & $36.1(34.3-38.0)$ & $45.4(42.8-47.9)$ \\
\hline Missing or unreported & $22.8(20.5-25.2)$ & $10.5(8.6-12.7)$ & $32.6(30.8-34.4)$ & $22.7(20.6-25.0)$ \\
\hline Low health status, \% (95\% CI) & $59.2(56.4-61.9)$ & $57.9(54.5-61.3)$ & $52.2(50.2-54.1)$ & $48.8(46.3-51.4)$ \\
\hline Functional disability, \% (95\% CI) & $78.7(76.2-80.9)$ & $79.4(76.3-82.2)$ & $84.8(83.4-86.1)$ & $86.4(84.5-88.0)$ \\
\hline $\begin{array}{l}\text { Mean modified Charlson } \\
\text { comorbidity score, \% ( } 95 \% \mathrm{CI})\end{array}$ & $1.58(1.50-1.67)$ & $1.83(1.73-1.94)$ & $1.71(1.65-1.76)$ & $2.06(1.99-2.13)$ \\
\hline
\end{tabular}

after adjusting for covariates. All of the analyses used SAScallable SUDAAN version 9.01 (Research Triangle Institute, Research Triangle Park, NC) to obtain proper variance estimates that accounted for the complex NHIS sampling design and results that were weighted to reflect national population estimates. 


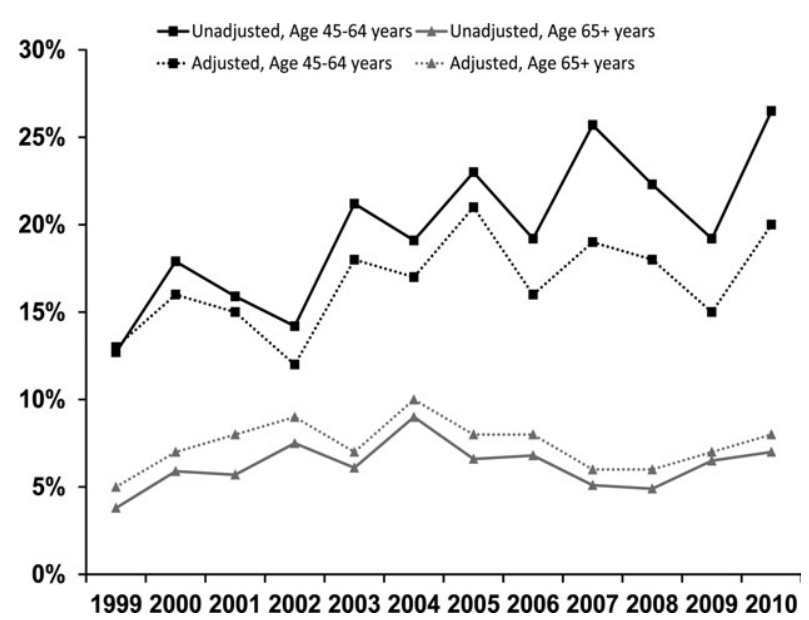

FIGURE : Percentage of US stroke survivors who did not get needed prescription drugs because of cost, by age group and year, before and after adjustment: National Health Interview Survey, 1999-2010. Adjusted for sex, race, Hispanic ethnicity, education, insurance, family income to poverty level ratio, health status, modified Charlson comorbidity score, and functional disability. $p=0.01$ for trend over time (chi-square test) from unadjusted model for age group 45 to 64 years. $p=0.21$ for trend over time (chisquare test) from unadjusted model for age group $\geq 65$ years. $p=0.08$ for trend over time (chi-square test) from fully adjusted model for age group 45 to 64 years. $p=0.90$ for trend over time (chi-square test) from fully adjusted model for age group $\geq 65$ years. Analyses accounted for the complex sampling design and used proper variance estimations to produce results that were weighted to reflect national population estimates.

\section{Standard Protocol Approvals, Registrations, and Patient Consents}

The University of Michigan Institutional Review Board ruled the project exempt.

\section{Results}

The sample included 8,673 stroke survivors aged $\geq 45$ years, representing an estimated 4.8 million US stroke survivors. Among all stroke survivors aged 45 years or older, the proportion who were aged 45 to 64 years increased from $33.4 \%$ in $1999-2005$ to $39.3 \%$ in 2006 2010 ( $p<0.001$ ). From 1999-2005 to 2006-2010, educational attainment, the family income to poverty ratio, and mean comorbidity score increased among stroke survivors above and below age 65 years (Table 1).

From 1999-2005 to 2006-2010, the proportion of stroke survivors aged 65 years or older with Medicare insurance increased from 92.9 to $96.4 \%(p<0.001)$. Between 2006 and 2010, we identified 2,083 stroke survivors aged 65 years or older with Medicare representing an estimated 1.3 million survivors, and 377 stroke survivors aged 45 to 64 years with Medicare representing an estimated 257,000 survivors. The proportion of stroke survivors with Medicare who reported Medicare Part D coverage was $50.5 \%$ in the age 45 to 64 years group and $39.7 \%$ in the age 65 years and older group. Among younger or older stroke survivors, Medicare Part D enrollees more frequently were women and had less education, lower income, and poorer health status than nonenrollees; in addition, Medicare Part D enrollees were more likely to have Medicaid insurance but less likely to have private insurance (Supplementary Table 1). Among the stroke survivors who were dually eligible for Medicare and Medicaid, 38\% of those aged 45 to 64 years and $16 \%$ of those aged 65 years or older reported Medicare Part D coverage.

\section{Temporal Trends in CRN Overall and by Age}

During the period from 1999 to $2010,11.4 \%$ of stroke survivors, representing approximately 543,000 individuals, reported CRN. Among stroke survivors aged 45 years or older, the prevalence of CRN increased from $6.5 \%$ in 1999 to $15.4 \%$ in 2010 ( $p_{\text {trend }}<0.001$ ). From 1999 to 2010 , the percentage of stroke survivors reporting CRN increased from 12.7 to $26.5 \%\left(p_{\text {trend }}=0.01\right)$ among those aged 45 to 64 years, and CRN increased nonsignificantly among those aged 65 years or older (from 3.8 to $7.0 \% ; p_{\text {trend }}=0.21 ;$ Fig). After adjustment for sociodemographics, clinical factors, and insurance, CRN did not increase significantly over the study period in those aged 45 to 64 years $\left(p_{\text {trend }}=0.08\right)$ or those aged 65 years or older ( $\mathrm{p}=0.90$; see Fig and Supplementary Table 2). Greater odds of CRN were associated with female gender, no health insurance, greater poverty, lower health status, more functional limitations, and higher comorbidity score (all $p<0.01$ ).

\section{Temporal Trends in CRN by Insurance Status}

Within the 45 to 64 years age group, rates of CRN increased among uninsured individuals (from $43.1 \%$ in $1999-2005$ to $57.1 \%$ in $2006-2010 ; p=0.03)$ and those with private insurance (from 8.6 to $13.6 \% ; p=$ 0.047); however, CRN remained stable among those with Medicare only or other insurance (Table 2). Among stroke survivors aged 65 years or older, CRN rates remained stable from 1999-2005 to 2006-2010 within each insurance group (Table 3). Sample size precluded subgroup analyses of temporal trends in CRN among younger adults with private and Medicare insurance and among older adults with private insurance only or no health insurance.

Among all stroke survivors aged 45 years or older with Medicare insurance, Medicare Part D enrollees more frequently reported CRN than nonenrollees (11.6 vs $6.6 \% ; p<0.001)$. Among those aged 65 years or older, CRN was higher among Medicare Part D 


\begin{tabular}{|c|c|c|c|c|c|c|}
\hline \multirow[t]{2}{*}{ Insurance Type } & \multicolumn{2}{|c|}{$\begin{array}{l}\text { Unadjusted Proportions } \\
\text { (SE), } \mathbf{n}=2,765\end{array}$} & \multirow{2}{*}{0.09} & \multicolumn{2}{|c|}{$\begin{array}{c}\text { Adjusted Proportions } \\
(\mathrm{SE}), \mathrm{n}=2,719\end{array}$} & \multirow{2}{*}{$\begin{array}{l}p \\
0.12\end{array}$} \\
\hline & $\begin{array}{l}\text { Years } \\
\text { 1999-2005 }\end{array}$ & $\begin{array}{l}\text { Years } \\
2006-2010\end{array}$ & & $\begin{array}{l}\text { Years } \\
\text { 1999-2005 }\end{array}$ & $\begin{array}{l}\text { Years } \\
2006-2010\end{array}$ & \\
\hline Private insurance only & $0.09(0.01)$ & $0.14(0.02)$ & & $0.12(0.02)$ & $0.18(0.03)$ & \\
\hline Medicare only & $0.34(0.04)$ & $0.32(0.05)$ & & $0.29(0.04)$ & $0.24(0.04)$ & \\
\hline Other & $0.18(0.02)$ & $0.18(0.02)$ & & $0.15(0.02)$ & $0.14(0.02)$ & \\
\hline Uninsured & $0.43(0.04)$ & $0.57(0.05)$ & & $0.47(0.04)$ & $0.52(0.05)$ & \\
\hline \multicolumn{7}{|c|}{$\begin{array}{l}\text { Adjusted proportion is predicted marginals after adjusting for sex, race, Hispanic ethnicity, education, family income to poverty } \\
\text { level ratio, health status, modified Charlson comorbidity score, and functional disability. Observations with missing data were } \\
\text { excluded from the regression models. Sample size precluded subgroup analysis in younger adults with private and Medicare } \\
\text { insurance. Analyses accounted for the complex sampling design and used proper variance estimations to produce results that were } \\
\text { weighted to reflect national population estimates. } \\
\text { SE = standard error. }\end{array}$} \\
\hline
\end{tabular}

participants than those without the drug benefit (7.7 vs $4.5 \% ; p=0.01)$. In the smaller group of stroke survivors younger than 65 years with Medicare coverage, similar albeit nonsignificant CRN differences between Medicare Part D enrollees and nonenrollees were seen (27.0 vs $19.4 \% ; p=0.20)$. After adjustment for sociodemographics, clinical factors, and insurance, CRN was similar among Medicare Part D enrollees and nonenrollees (Table 4).

\section{Discussion}

In this nationally representative sample, $11 \%$ of stroke survivors, an estimated 543,000 individuals, experienced CRN during the period of 1999-2010. CRN increased significantly among stroke survivors aged 45 to 64 years from 1999-2005 to 2006-2010, particularly among those with no health insurance (from 43 to $57 \%$ ). CRN remained relatively stable among stroke survivors aged 65 years and older. Among older stroke survivors with Medicare coverage, CRN was 2-fold greater among Medicare Part D enrollees than those without the drug benefit. Although differences in sociodemographics, clinical factors, and health insurance between Medicare Part D enrollees and nonenrollees explained this apparent paradox, our results demonstrate that Medicare Part D has not solved the problem of CRN for many stroke survivors.

CRN was more common among older stroke survivors who enrolled in Medicare Part D than those who did not. This apparent paradox may be explained by the characteristics of early Medicare Part D adopters.

\section{TABLE 3: Proportion (and Standard Error) of Stroke Survivors Aged 65 Years or Older Not Able to Afford Prescription Medication, by Age Group and Time: National Health Interview Survey, 1999-2010}

\begin{tabular}{|c|c|c|c|c|c|c|}
\hline \multirow[t]{3}{*}{ Insurance Type } & \multicolumn{2}{|c|}{$\begin{array}{c}\text { Unadjusted Proportions } \\
(\mathrm{SE}), \mathbf{n}=5,155\end{array}$} & \multirow{3}{*}{$\begin{array}{l}p \\
0.91\end{array}$} & \multicolumn{2}{|c|}{$\begin{array}{l}\text { Adjusted Proportions } \\
(\mathrm{SE}), \mathrm{n}=5,032\end{array}$} & \multirow{3}{*}{$\begin{array}{l}p \\
0.95\end{array}$} \\
\hline & Years & Years & & Years & Years & \\
\hline & 1999-2005 & 2006-2010 & & 1999-2005 & 2006-2010 & \\
\hline Private and Medicare & $0.04(0.01)$ & $0.04(0.01)$ & & $0.05(0.01)$ & $0.04(0.01)$ & \\
\hline Medicare only & $0.10(0.01)$ & $0.10(0.01)$ & & $0.10(0.01)$ & $0.09(0.01)$ & \\
\hline Medicare and Medicaid & $0.10(0.02)$ & $0.10(0.02)$ & & $0.06(0.01)$ & $0.05(0.01)$ & \\
\hline \multicolumn{7}{|c|}{$\begin{array}{l}\text { Adjusted proportion is predicted marginals after adjusting for sex, race, Hispanic ethnicity, education, family income to poverty } \\
\text { level ratio, health status, modified Charlson comorbidity score, and functional disability. Observations with missing data were } \\
\text { excluded from the regression models. Sample size precluded subgroup analysis in older adults with private insurance only or no } \\
\text { health insurance. Analyses accounted for the complex sampling design and used proper variance estimations to produce results that } \\
\text { were weighted to reflect national population estimates. }\end{array}$} \\
\hline
\end{tabular}




\section{TABLE 4: Proportion (and Standard Error) of Stroke Survivors with Medicare Insurance Not Able to Afford Prescription Medication, by Age Group and Medicare Part D Status: National Health Interview Survey, 2006-2010}

\begin{tabular}{|c|c|c|c|c|c|c|}
\hline \multirow[t]{3}{*}{ Adjusted Status } & \multicolumn{6}{|c|}{ Proportions (SE) } \\
\hline & \multicolumn{3}{|c|}{$\begin{array}{l}\text { Age 45-64 Years, } \\
\quad n=358\end{array}$} & \multicolumn{3}{|c|}{$\begin{aligned} \text { Age } & \geq 65 \text { Years } \\
n & =1,975\end{aligned}$} \\
\hline & $\begin{array}{l}\text { Medicare } \\
\text { Part D }\end{array}$ & $\begin{array}{l}\text { No Medicare } \\
\text { Part D }\end{array}$ & $p$ & $\begin{array}{l}\text { Medicare } \\
\text { Part D }\end{array}$ & $\begin{array}{l}\text { No Medicare } \\
\text { Part D }\end{array}$ & $p$ \\
\hline Unadjusted & $0.27(0.04)$ & $0.19(0.04)$ & 0.20 & $0.08(0.01)$ & $0.04(0.01)$ & 0.01 \\
\hline $\begin{array}{l}\text { Partially adjusted: all except } \\
\text { health insurance }\end{array}$ & $0.25(0.04)$ & $0.21(0.04)$ & 0.54 & $0.07(0.01)$ & $0.05(0.01)$ & 0.09 \\
\hline $\begin{array}{l}\text { Fully adjusted: includes } \\
\text { health insurance }\end{array}$ & $0.25(0.04)$ & $0.24(0.05)$ & 0.96 & $0.07(0.01)$ & $0.06(0.01)$ & 0.35 \\
\hline \multicolumn{7}{|c|}{$\begin{array}{l}\text { Partially adjusted proportion is predicted marginals after adjusting for sex, race, Hispanic ethnicity, education, family income to } \\
\text { poverty level ratio, health status, modified Charlson comorbidity score, and functional disability. Fully adjusted proportion also } \\
\text { included health insurance (private, Medicaid, or neither). Observations with missing data were excluded from the regression mod- } \\
\text { els. Analyses accounted for the complex sampling design and used proper variance estimations to produce results that were } \\
\text { weighted to reflect national population estimates. } \\
\text { SE = standard error. }\end{array}$} \\
\hline
\end{tabular}

Compared to those who did not enroll, the stroke survivors who enrolled in Medicare Part D more frequently reported risk factors for $\mathrm{CRN},{ }^{22}$ including less education, poor health status, low income, and less private insurance coverage, similar to other reports. ${ }^{26,27}$ After accounting for these differences, CRN did not differ by Medicare Part D enrollment. However, our results show that CRN remains high for a substantial portion of older adults with stroke, despite the Medicare Part D drug benefit.

Given that Medicare Part D is associated with small, but significant, reductions in CRN, ${ }^{28,29}$ it is possible that the positive effects of Medicare Part D on CRN mitigated the negative effects of the economic recession and the rising use and costs of medications, thus resulting in relatively stable prevalence of CRN among the older stroke survivors in our study. Another explanation is that the drug benefit may be less effective at reducing CRN among the sickest beneficiaries who have persistently elevated rates of CRN. ${ }^{28,29}$ This observation may partly explain why the older stroke survivors with Medicare coverage in our study had stable, not decreased, CRN after Medicare Part D implementation. Furthermore, stroke survivors enrolled in Medicare Part D still have high out-of-pocket expenditures due to rising Medicare Part D drug prices ${ }^{30}$ or reaching the "doughnut hole," a gap in prescription drug coverage occurring in nearly half of patients taking medication for stroke or myocardial infarction. ${ }^{27}$ Although the Affordable Care Act would reduce Part D enrollees' drug costs in the gap using federal and manufacturer subsidies and by lowering the limit for catastrophic coverage, it is unknown how these changes will impact CRN in stroke survivors.

Our findings also suggest potential underutilization of Medicare Part D, particularly by chronically ill adults living in poverty. Of stroke survivors who were Medicare beneficiaries, only half of those aged 45 to 64 years and $40 \%$ of those aged 65 years or older reported Medicare Part D coverage. These percentages are consistent with previous reports of Medicare Part D coverage by $38 \%$ of older adults in an ongoing, longitudinal, biracial population-based study and by $50 \%$ of older adults in a national sample of noninstitutionalized Medicare beneficiaries. $^{26,31}$ Some NHIS respondents may have been unaware of their eligibility for Medicare Part D coverage. For example, the Centers for Medicare and Medicaid Services assigned adults eligible for both Medicare and Medicaid to Part D prescription drug plans. However, among the dually eligible adults in our study, only $38 \%$ of those aged 45 to 64 years and $16 \%$ of those aged 65 years or older reported Medicare Part D enrollment. Taken together, these data suggest a missed educational opportunity for Medicare Part D and low-income subsidy participation. ${ }^{26,31}$

Adults younger than 65 years with chronic illness have substantial financial burdens for health care. ${ }^{5,17}$ This problem may be worse among stroke patients, given that the average US stroke survivor takes 11 different medications (range, 3-27 medications), ${ }^{16}$ and prescription medication accounts for 35 to $50 \%$ of total out-ofpocket medical expenses. ${ }^{17}$ In 2003 , approximately 55\% 
of stroke survivors younger than 65 years spent $>10 \%$ of family income on health care and about 30\% of stroke survivors spent $>20 \%$ of family income on health care. ${ }^{17}$ Potential explanations of a more significant problem affording medication in younger stroke survivors include differences in competing household costs (eg, mortgage/ rent and childcare) or insurance cost-sharing, which could not be assessed directly in our analysis.

Among uninsured stroke survivors younger than 65 years, we found that the high rates of CRN increased further during the recession, when nearly 6 in 10 stroke survivors were unable to afford prescription medications. Changes in income and number of medications among this group may partially explain this trend, because the temporal increase in CRN was diminished after adjusting for income, health status, and comorbidity. The Affordable Care Act is expected to reduce the number of uninsured adults through Medicaid expansion and subsidized health insurance, even for those with pre-existing conditions like stroke. ${ }^{32}$ However, our study and others ${ }^{26,28,33}$ suggest that insurance coverage alone likely will not eliminate CRN or its negative effect on disease control in chronically ill adults.

Despite federal and local programs, medication is still unaffordable for many stroke survivors. Temporal increases in the number and cost of stroke preventive medications potentially increased the cost of adherence for stroke patients. During the study period, there were significant increases in the prescription of antithrombotic agents (aspirin-extended release dipyridamole ${ }^{34}$ and clopidogrel $^{34,35}$ ) and statins ${ }^{36}$ to stroke survivors. Although less is known about trends in the prescription of highcost antihypertensive agents like ramipril to stroke survivors, the use of angiotensin-converting enzyme inhibitors or angiotensin II receptor blockers increased from 39 to $69 \%$ in survivors of acute myocardial infarction, a related vascular disease, between 1997 and 2006. ${ }^{37}$

Newer antithrombotic drugs are efficacious in preventing stroke in patients with nonvalvular atrial fibrillation, ${ }^{38-40}$ but the drugs' costs will increase the cost of adherence for stroke patients. The 2 available drugs, dabigatran and rivaroxaban, each cost $\sim \$ 8.50 /$ day (www.costco.com). Dabigatran prescriptions have soared, with most prescriptions being for primary or secondary stroke prevention. ${ }^{35}$ Because dabigatran has a shorter half-life than warfarin, its benefit and cost-effectiveness will be reduced in nonadherent patients. ${ }^{41,42}$ Although the effect of CRN on health outcomes in stroke patients could not be assessed directly in our current study, nonadherence to secondary preventive medications increases the risk of recurrent vascular events and death in myocardial infarction patients ${ }^{3,43}$ and stroke patients. ${ }^{44,45}$
Our study has several limitations. The NHIS includes only community-dwelling, noninstitutionalized stroke survivors, and results may only be generalized to this population. These self-reported NHIS data, including stroke history, may lead to misclassification. Although clinical information of stroke history was not available, recent reports suggest high self-reported stroke accuracy, even in the disabled elderly, with sensitivity rates ranging from 80 to $98 \%{ }^{46,47}$

Proxy reports may over- or underestimate medication adherence. Although self-report measures can be biased by inaccurate recall or by social desirability (ie, individuals overestimate or inflate adherence), ${ }^{48}$ patient self-report of medication nonadherence agrees with pharmacy claims data ${ }^{49}$ and is strongly associated with adverse events, including stroke and death, among adults with known cardiovascular disease. ${ }^{1-3}$

The NHIS does not include provider characteristics (eg, prescribing behavior or knowledge of patients' ability to pay) or patient-level information on the number and costs of medications, pill counts, pharmacy claims, and the magnitude or severity of CRN (ie, the number or type of medications foregone due to cost). Although the NHIS does not ascertain the number of medications, we included a proxy variable, number of conditions. In addition, the NHIS measure of CRN does not include taking fewer pills than prescribed, so our CRN estimates may be low. The comorbidity score did not include disease severity, acquired immunodeficiency syndrome, or peripheral vascular disease and so may underestimate comorbidity. The effect of temporal changes in the number or cost of medications on CRN in stroke survivors cannot be assessed in these NHIS data.

In conclusion, we found that CRN increased significantly between 1999-2005 and 2006-2010 among younger stroke survivors, particularly those who were uninsured. There was no evidence that Medicare Part D coverage decreased CRN among stroke survivors during this time period. There were a considerable number of stroke survivors who were unaware of their eligibility for Medicare Part D.

\section{Acknowledgment}

D.A.L. received research support from the NIH (NIA P30 AG024824-07, NIDDK P30 DK092926 and NIA K23 AG040278).

\section{Potential Conflicts of Interest}

K.M.L.: grants/grants pending, NIH/NIA. 


\section{REFERENCES}

1. Heisler M, Langa KM, Eby EL, et al. The health effects of restricting prescription medication use because of cost. Med Care 2004; 42:626-634

2. Heisler $M$, Choi $H$, Rosen $A B$, et al. Hospitalizations and deaths among adults with cardiovascular disease who underuse medications because of cost: a longitudinal analysis. Med Care 2010;48:87-94.

3. Rahimi AR, Spertus JA, Reid KJ, et al. Financial barriers to health care and outcomes after acute myocardial infarction. JAMA 2007; 297:1063-1072

4. McHorney CA, Spain CV. Frequency of and reasons for medication non-fulfillment and non-persistence among American adults with chronic disease in 2008. Health Expect 2011;14:307-320.

5. Piette JD, Rosland AM, Silveira MJ, et al. Medication cost problems among chronically ill adults in the US: did the financial crisis make a bad situation even worse? Patient Prefer Adherence 2011; 5:187-194.

6. Love J. The economic slowdown's impact on middle-aged and older Americans. Washington, DC: AARP, May 2008. Available at: http://assets.aarp.org/rgcenter/econ/economy_survey.pdf Accessed December 16, 2011

7. Collins SR, Doty MM, Robertson R, Garber T. Help on the horizon. How the recession has left millions of workers without health insurance, and how health reform will bring relief. Findings from the Commonwealth Fund Biennial Health Insurance Survey of 2010. March 2011. Available at: http://www.commonwealthfund.org/ / media/Files/Publications/Fund\%20Report/2011/Mar/1486_Collins_ help_on_the_horizon_2010_biennial_survey_report_FINAL_v2.pdf Accessed December 16, 2011

8. Roger VL, Go AS, Lloyd-Jones DM, et al. Heart disease and stroke statistics-2011 update: a report from the American Heart Association. Circulation 2011;123:e18-e209.

9. Heidenreich PA, Trogdon JG, Khavjou OA, et al. Forecasting the future of cardiovascular disease in the United States: a policy statement from the American Heart Association. Circulation 2011; 123:933-944

10. Samsa GP, Bian J, Lipscomb J, Matchar DB. Epidemiology of recurrent cerebral infarction: a Medicare claims-based comparison of first and recurrent strokes on 2-year survival and cost. Stroke $1999 ; 30: 338-349$

11. Collaborative overview of randomised trials of antiplatelet therapy-1,: Prevention of deathmyocardial infarction, and stroke by prolonged antiplatelet therapy in various categories of patients. Antiplatelet Trialists' Collaboration. BMJ 1994;308:81-106.

12. Randomised trial of a perindopril-based blood-pressure-lowering regimen among 6,105 individuals with previous stroke or transient ischaemic attack. Lancet 2001;358:1033-1041.

13. Amarenco P, Bogousslavsky J, Callahan Alll, et al. High-dose atorvastatin after stroke or transient ischemic attack. $\mathrm{N}$ Engl J Med 2006;355:549-559.

14. Halkes PH, van Gijn J, Kappelle LJ, et al. Aspirin plus dipyridamole versus aspirin alone after cerebral ischaemia of arterial origin (ESPRIT): randomised controlled trial. Lancet 2006;367:1665-1673.

15. Hankey GJ, Warlow CP. Treatment and secondary prevention of stroke: evidence, costs, and effects on individuals and populations. Lancet 1999;354:1457-1463.

16. Ostwald SK, Wasserman J, Davis S. Medications, comorbidities, and medical complications in stroke survivors: the CAReS study. Rehabil Nurs 2006;31:10-14.

17. Banthin JS, Bernard DM. Changes in financial burdens for health care: national estimates for the population younger than 65 years, 1996 to 2003. JAMA 2006;296:2712-2719.

18. The National Center for Health Statistics, National Health Interview Survey. Available at: http://www.cdc.gov/nchs/nhis.htm Accessed December 16, 2011
19. Piette JD, Heisler M, Wagner TH. Medication characteristics beyond cost alone influence decisions to underuse pharmacotherapy in response to financial pressures. J Clin Epidemiol 2006;59: 739-746

20. Goldman DP, Joyce GF, Escarce JJ, et al. Pharmacy benefits and the use of drugs by the chronically ill. JAMA 2004;291:2344-2350.

21. Roth GA, Morden NE, Zhou W, et al. Clopidogrel use and early outcomes among older patients receiving a drug-eluting coronary artery stent. Circ Cardiovasc Qual Outcomes 2012;5:103-112.

22. Levine DA, Kiefe $\mathrm{Cl}$, Houston TK, et al. Younger stroke survivors have reduced access to physician care and medications: National Health Interview Survey from years 1998 to 2002. Arch Neurol 2007;64:37-42

23. Medicare.gov. The official US government site for people with Medicare. Available at: http://www.medicare.gov Accessed August 31, 2012.

24. Gelberg L, Andersen RM, Leake BD. The Behavioral Model for Vulnerable Populations: application to medical care use and outcomes for homeless people. Health Serv Res 2000;34:1273-1302.

25. Goldstein LB, Samsa GP, Matchar DB, Horner RD. Charlson Index comorbidity adjustment for ischemic stroke outcome studies. Stroke 2004;35:1941-1945.

26. Neuman P, Strollo MK, Guterman S, et al. Medicare prescription drug benefit progress report: findings from a 2006 national survey of seniors. Health Aff (Millwood) 2007;26:w630-w643.

27. Pedan A, Lu J, Varasteh LT. Assessment of drug consumption patterns for Medicare Part D patients. Am J Manag Care 2009;15: 323-327.

28. Yin W, Basu A, Zhang JX, et al. The effect of the Medicare Part D prescription benefit on drug utilization and expenditures. Ann Intern Med 2008;148:169-177.

29. Madden JM, Graves AJ, Zhang F, et al. Cost-related medication nonadherence and spending on basic needs following implementation of Medicare Part D. JAMA 2008;299:1922-1928.

30. Schondelmeyer SW, Purvis, L. Rx price watch report, March 2012 trends in retail prices of prescription drugs widely used by Medicare beneficiaries 2005 to 2009. Available at: http://www.aarp.org/ppi Accessed March 13, 2012

31. Skarupski KA, de Leon CF, Barnes LL, Evans DA. Medicare part D enrollment in a biracial community-based population of older adults. Gerontologist 2009;49:828-838.

32. Schoen C, Doty MM, Robertson RH, Collins SR. Affordable Care Act reforms could reduce the number of underinsured US adults by 70 percent. Health Aff (Millwood) 2011;30:1762-1771.

33. Ngo-Metzger $\mathrm{Q}$, Sorkin DH, Billimek J, et al. The effects of financial pressures on adherence and glucose control among racial/ ethnically diverse patients with diabetes. J Gen Intern Med 2012; 27:432-437.

34. Menon BK, Frankel MR, Liang L, et al. Rapid change in prescribing behavior in hospitals participating in get with the guidelinesstroke after release of the Management of Atherothrombosis with Clopidogrel in High-Risk Patients (MATCH) clinical trial results. Stroke 2010;41:2094-2097.

35. Kirley K, Qato DM, Kornfield R, et al. National trends in oral anticoagulant use in the United States, 2007 to 2011. Circ Cardiovasc Qual Outcomes 2012:5:615-621.

36. Ovbiagele B, Schwamm LH, Smith EE, et al. Recent nationwide trends in discharge statin treatment of hospitalized patients with stroke. Stroke 2010;41:1508-1513.

37. Jernberg $T$, Johanson $P$, Held $C$, et al. Association between adoption of evidence-based treatment and survival for patients with STelevation myocardial infarction. JAMA 2011;305:1677-1684.

38. Connolly SJ, Ezekowitz MD, Yusuf S, et al. Dabigatran versus warfarin in patients with atrial fibrillation. N Engl J Med 2009;361:1139-1151. 
39. Patel MR, Mahaffey KW, Garg J, et al. Rivaroxaban versus warfarin in nonvalvular atrial fibrillation. N Engl J Med 2011;365: 883-891.

40. Granger CB, Alexander JH, McMurray JJ, et al. Apixaban versus warfarin in patients with atrial fibrillation. N Engl J Med 2011;365: 981-992.

41. Gage BF. Can we rely on RE-LY? N Engl J Med 2009;361: 1200-1202

42. Gage BF. Cost of dabigatran for atrial fibrillation. BMJ 2011;343: d6980.

43. Spertus JA, Kettelkamp R, Vance C, et al. Prevalence, predictors, and outcomes of premature discontinuation of thienopyridine therapy after drug-eluting stent placement: results from the PREMIER registry. Circulation 2006;113:2803-2809.

44. Colivicchi F, Bassi A, Santini M, Caltagirone C. Discontinuation of statin therapy and clinical outcome after ischemic stroke. Stroke 2007;38:2652-2657.
45. Khan NA, Yun L, Humphries K, Kapral M. Antihypertensive drug use and adherence after stroke: are there sex differences? Stroke 2010;41:1445-1449.

46. Simpson CF, Boyd CM, Carlson MC, et al. Agreement between self-report of disease diagnoses and medical record validation in disabled older women: factors that modify agreement. J Am Geriatr Soc 2004;52:123-127.

47. Heckbert SR, Kooperberg C, Safford MM, et al. Comparison of self-report, hospital discharge codes, and adjudication of cardiovascular events in the Women's Health Initiative. Am J Epidemiol 2004;160:1152-1158.

48. Ho PM, Bryson CL, Rumsfeld JS. Medication adherence: its importance in cardiovascular outcomes. Circulation 2009;119:3028-3035.

49. Pit SW, Byles JE, Cockburn J. Accuracy of telephone self-report of drug use in older people and agreement with pharmaceutical claims data. Drugs Aging 2008;25:71-80. 